\title{
Combining Amino Acid and Vitamin D Supplementation with Exercise Training Increases Skeletal Muscle Mass and Prevent Bone Mineral Density Loss in Participants with Low Muscle Mass
}

\author{
Ha Cao Thi Thu ${ }^{1,2}$, Satoshi Kurose ${ }^{1}$, Yaeko Fukushima ${ }^{1}$, Nana Takao ${ }^{1,3}$, Natsuko Nakamura ${ }^{3}$, Akiko Kitamura ${ }^{3}$, \\ Kyoko Higurashi ${ }^{1}$, Tomohiro Kamo ${ }^{1}$, Sawako Yoshiuchi ${ }^{3}$, Katsuko Onishi ${ }^{1}$, Hiromi Tsutsumi ${ }^{1} \&$ Yutaka \\ Kimura ${ }^{1,3}$ \\ ${ }^{1}$ Department of Health Science, Graduate School of Medicine, Kansai Medical University, Japan \\ ${ }^{2}$ Department of Adult Nutrition Counseling, National Institute of Nutrition, Hanoi, Vietnam \\ ${ }^{3}$ Health Science Center, Kansai Medical University Hirakata Hospital, Japan \\ Correspondence: Ha Cao Thi Thu, Department of Health Science, Graduate School of Medicine, Kansai Medical \\ University, 2-5-1, Shinmachi, Hirakata, Osaka, 573-1191, Japan. Tel: 81-72-804-2334; Fax: 81-72-804-2821. \\ E-mail: caoha@hirakata.kmu.ac.jp
}

Received: November 12, 2017 Accepted: December 13, 2017 Online Published: December 18, 2017

doi:10.5539/gjhs.v10n2p28 URL: https://doi.org/10.5539/gjhs.v10n2p28

\begin{abstract}
This study evaluated the impact of exercise training with amino acid and vitamin D supplementation on muscle and bone mass in participants with low muscle volume. Twenty-nine Japanese participants (56-84 years old) were enrolled and assigned into the supplement $(n=15)$ and non-supplement $(n=14)$ groups. All participants underwent a 6-month exercise program. Supplements and nutrition support were provided to the participants in the supplement group for 12 weeks. Body composition and whole bone mineral density (BMD) were measured using dual energy $\mathrm{x}$-ray absorptiometry. The outcomes, including body composition, whole $\mathrm{BMD}$, and skeletal muscle mass index (SMI), were evaluated twice: pre- and post-intervention. The SMI was $6.51(6.28 ; 7.14)$ and $5.58(5.24 ; 6.05)$ $\left(\mathrm{kg} / \mathrm{m}^{2}\right)$ in men and women, respectively. The average SMI change was $0.13 \%(-0.05 \% ; 0.31 \%)$ and $2.33 \%$ $(-0.88 \% ; 5.48 \%)$; [mean (lower; upper quartile)]. The average BMD loss in the non-supplement group was $-2.78 \%$, and the BMD increased in the supplement group by $4.34 \%$; there was an absolute difference between the two groups $(p<0.05)$. After the intervention, serum myostatin was changed ( $p=0.001$, non-supplement $>$ supplement), serum vitamin $\mathrm{D}$ was increased ( $\mathrm{p}=0.03$; supplement $>$ non-supplement), and $\mathrm{BMD}$ was maintained $(\mathrm{p}=0.03$, supplement $>$ non-supplement). There was a significant difference in the serum myostatin level at baseline and at 6 -month in the non-supplement group, with a mean difference of $0.48 \mathrm{ng} / \mathrm{ml}(\mathrm{p}=0.01)$. There was no significant improvement in the total lean mass, and handgrip strength. Resistance exercise combined with an amino acid supplement affects muscle and bone mass in the short-term intervention.
\end{abstract}

Keywords: amino acid supplement; body composition; bone mineral density; skeletal muscle index; myostatin; vitamin D

\section{Introduction}

Sarcopenia is characterized by a loss of muscle mass and strength related to aging, and leads to physical disability, the decline in muscle function, falling, fractures, and increased risk of mortality (Cruz-Jentoft et al., 2010). More importantly, sarcopenia is associated with diseases that increase over time, especially in aging people. Older adults experience a progressive, generalized loss of skeletal muscle and decrease in physical function, with an inherent risk of disability, poor quality of life, and death (Morley, Baumgartner, Roubenoff, Mayer, \& Nair, 2001). Sarcopenia has become common worldwide and is associated with high financial costs; hence, it is important to treat sarcopenia to maintain muscle mass, improve strength, reduce the risk of falling, and increase the life span of the elderly population.

Many factors such as insufficient physical activities, chronic disease, and decreased muscle protein synthesis may lead to the loss of muscle mass (Iannuzzi-Sucich, Prestwook, \& Kenny, 2002), but the potentially preventable strategy is based only on nutritional deficiency and skeletal muscle dysfunction with targeted interventions (Fiatarone et al., 1994). Growing evidence suggests that insufficient protein, energy, and certain micronutrients 
intake may consequently lead to secondary sarcopenia (Cerri et al., 2015). Nutrition intake can positively impact protein synthesis; therefore, interventions for sarcopenia usually include nutrition. Increasing the recommended dietary intake (quantity) and the essential amino acids (quality) of dietary protein can stimulate muscle protein anabolism in elderly people (Houston et al., 2008; Børsheim et al., 2008).

Stimulating gene expression, enhancing muscle protein synthesis and facilitating neuromuscular function were achieved by increasing vitamin D intake (Wicherts et al., 2007; Ceglia \& Harris, 2013), and improving muscle strength and balance (Latham et al., 2003; Muir and Montero-Odasso, 2011). Vitamin D intake also declined the inflammation related to the slowdown of muscle strength in the elderly population (Schaap et al., 2006). The recommended nutritional intake includes high-quality protein and vitamin $\mathrm{D}$, which are necessary to minimize the loss of muscle mass and its adverse effects in elderly (Waters et al., 2010; Candow et al., 2012). The decline of muscle mass and muscle function was addressed by physical training (Latham et al., 2004). Adding dynamic physical activity to resistance exercise also contributes substantially to improve physical function (Liu and Latham, 2009). Age and a decrease in nutrition are related (Forbes et al., 2012), and nutrition is an important modulator of health and well-being in the elderly. Inadequate nutritional intake may play a significant role in the metabolic control system and the progression of many lifestyle-related diseases.

Therefore, we designed a study that combined amino acids and a vitamin D supplement with regular physical activity. We tested whether, compared with non-supplementation, supplementation would increase the skeletal muscle index (SMI) and muscle mass while improving strength, nutritional status, and physical function.

\section{Methods}

\subsection{Ethical Considerations}

The study procedure and protocol were approved by the Institutional Review Board of Kansai Medical University (ethical documentation number: 000013445), and the study was performed according to the ethical principles of the Declaration of Helsinki. All participants gave written informed consent to participate.

\subsection{Study Design and Participants}

The present study was designed as an interventional investigation with supplementation and control (non-supplementation) groups. We recruited 19 participants, with low muscle mass who visited our health science center. The inclusion criteria were: participants aged 56 years and older who completed our intervention program and those with an appendicular lean mass divided by height squared (SMI), of $<7.77$ and $<6.12 \mathrm{~kg} / \mathrm{m}^{2}$ for men and women, respectively. We excluded the participants with severe liver, heart, and kidney dysfunction; thyroid disorders; cancers; arthritis; laboratory abnormalities; BMI $>25 \mathrm{~kg} / \mathrm{m}^{2}$, and who were treated with steroids or heparin (3 persons). In the later period, we also recruited 18 other participants according to the previous inclusion and exclusion criteria. Three patients dropped out of the study and were excluded. Ultimately, the study included 29 participants. The details of study design are shown in Figure 1.

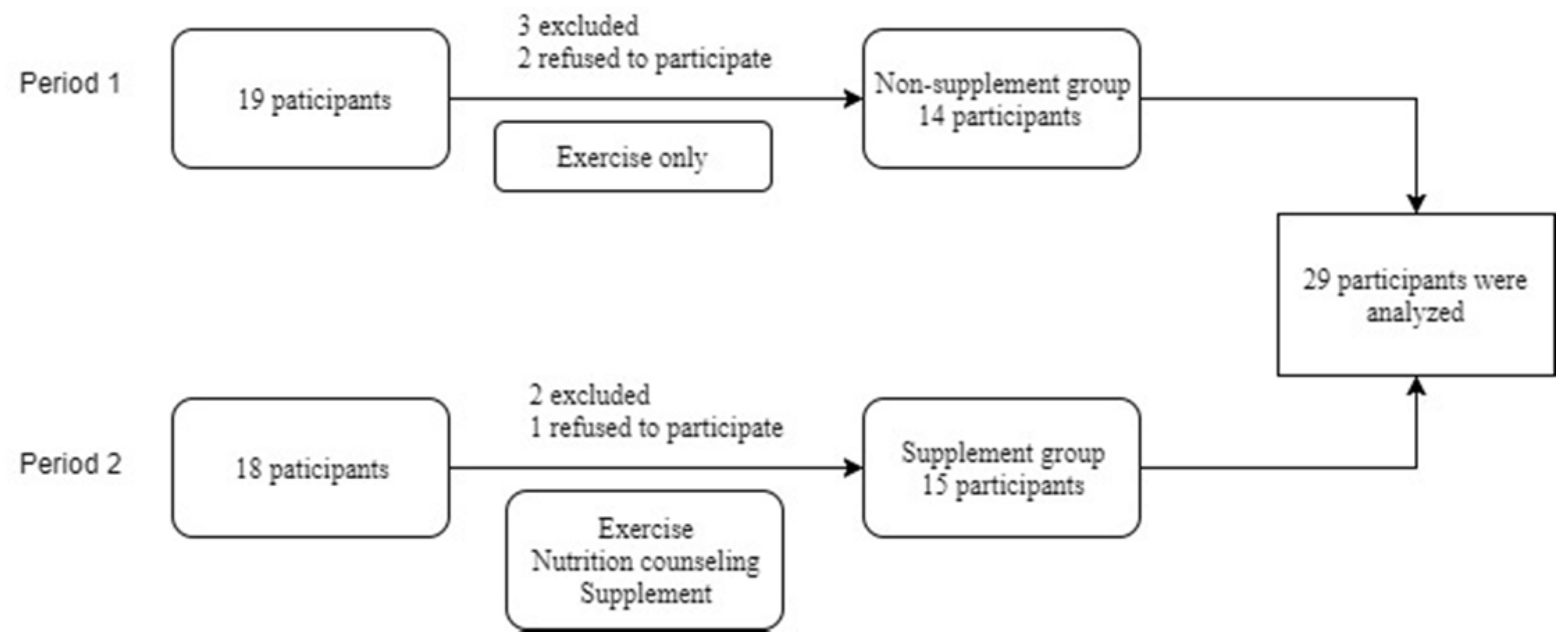

Figure 1. Flow diagram of study design 


\subsection{Intervention Procedures}

Participants were examined by a physician for a medical consultation, underwent nutritional counseling, and received instructions on how to perform the physical exercise. Direct interviews were conducted to review the participant's lifestyle regarding the intervention, to educate them about healthy eating behavior, and to develop a personalized plan for nutritional intake to maximize the participant's protein intake behavior. Participants were instructed to keep their energy intake to the healthy weight $\times 25-35 \mathrm{kcal} /$ day, and protein intake to healthy weight $\times 1.2 \mathrm{~g} / \mathrm{kg} /$ day (Bauer et al., 2013). Recommended dietary fat and other nutrients intake was in accordance with the "Dietary Reference Intakes for Japanese (2015)". Healthy weight was calculated for each participant using the standard body mass index of $22\left(\mathrm{~kg} / \mathrm{m}^{2}\right)$ :

$$
\text { healthy weight }=22 \times \text { height }^{2}
$$

Qualified dieticians conducted the monthly nutritional counseling. Exercise therapy was administered beginning at week 2 . Each patient visited the health science center eight times a month for physical training and was followed up at 6-month.

\subsection{Exercise Therapy}

Physical activity, including a gravity level resistance exercise, was prescribed. The exercise duration was 60 min per day at the anaerobic threshold intensity level, 2 days per week, at our health science center under the supervision of qualified health fitness trainers. Prior to undertaking the exercise, each participant was evaluated using a symptom-limited cardiopulmonary exercise to determine the anaerobic threshold and peak oxygen uptake. In addition, the participants were instructed on how to perform the exercises at home, and were provided with weight instruments to help them perform these exercises. All the participants adhered to the prescribed intervention.

\subsection{Outcome Measurement}

The outcomes were evaluated according to the data collected from the interviews, muscle mass assessments, and physical function tests at baseline and at the 6-month follow-up interval. The participant's body weight was measured on an electronic scale while he or she was barefoot and wearing light weight clothing. Standing height was measured without shoes, using a portable stadiometer with the mandibular plane parallel to the floor. The BMI was calculated as the whole-body weight divided by height squared. The SMI was calculated as the sum of the lean mass of both arms and legs divided by height squared. The handgrip dynamometer was used for evaluating handgrip strength (HGS). The maximum strength of the dominant hand of each participant was measured three times, and the average value was recorded. The usual and fastest walking speed was measured by determining the time that was required to walk a $10-\mathrm{m}$ distance. The leg strength was evaluated using a recumbent ergometer (Strength Ergo; Mitsubishi Electric Corp., Tokyo, Japan). The maximum strength of the left and right legs of each participant was measured, and then the average value was calculated. Finally, these values were corrected for body weight $(\mathrm{Nm} / \mathrm{kg})$. During the test, recumbent ergometer settings were changed for each subject for standardization.

\subsection{Laboratory Measures}

Blood samples were obtained from the cubital vein via plastic tubes that were enclosed in a vacuum, between 8:30 and 10:00 AM after the participant had fasted for $8 \mathrm{~h}$. We measured the peripheral and biochemical data, as well as myokines. The blood test was performed using a hospital autoanalyzer and it included: complete blood cell counts; neutrophil counts; hemoglobin, albumin, and fasting plasma glucose concentrations; estimated GFR, and lipid profile. The blood samples were centrifuged at $4{ }^{\circ} \mathrm{C}$ and $3,000 \mathrm{rpm}$ for $10 \mathrm{~min}$ and placed in a container for serum storage at $-80^{\circ} \mathrm{C}$ until an enzyme-linked immunosorbent assay for serum myostatin (GDF-8/Myostatin Quantikine ELISA Kit, DGDF80, R\&D Systems, Minneapolis, MN, USA) was performed using a Powerscan HT plate reader (DS Pharma Biomedical Co., Ltd., Osaka, Japan) and a chemiluminescent immunoassay for vitamin D (LIAISON 25 OH Vitamin D Total, DiaSorin S.p.A, Saluggia, Italy).

\subsection{Body Composition}

The whole-body composition was measured using dual energy x-ray absorptiometry (DXA) (QDR 4,500A, Hologic Inc., Bedford, MA, USA). The coefficient of variation for the lean mass measurements and bone mineral density was less than $3 \%$ and $1.5 \%$, respectively. The fat and lean mass data and whole-body bone data were derived from a whole-body scan. The bone mineral content (BMC), fat mass, and lean soft tissue mass were measured separately for each part of the body, including the arms and legs. The SMI was calculated as the total mass of the arms and legs in the kilogram, divided by height in meters squared. All measurements were performed by the same technicians who used a standard operating procedure. The machine was calibrated using a standard 
phantom before each measurement.

\subsection{Hand Grip Strength}

HGS was obtained using a handgrip dynamometer (Sammons Preston Rolyan Co, Bolingbrook, IL, USA). The HGS of each participant was measured three times for the maximum strength of the right and left hands, and then the average value was calculated.

\subsection{Dietary Supplement}

Amino acid supplements were provided to the participants in the supplement group every 2 weeks. Packets of jelly amino acid supplements, "Amino L40" (Ajinomoto, Tokyo, Japan), with $3 \mathrm{~g}$ of amino acids ( $40.0 \%$ leucine, $10.0 \%$ isoleucine, $10.0 \%$ valine, and $40 \%$ other) and $800 \mathrm{IU}$ of vitamin D were provided to the participants, who were instructed to take the 3-g supplement twice daily $(6 \mathrm{~g})$ for 12 weeks after breakfast and dinner. To monitor the participant's amino acid intake accurately, we provided them with record sheets that were collected every 2 weeks. Each participant recorded the amount and the time the supplement was taken every day.

\subsection{Statistical Analysis}

The statistical analysis of the data was designed to address the study's primary aims. The characteristics of the participants and other variables are presented as medians (lower and upper quartiles). The non-normal distribution data were checked by using the Shapiro-Wilk test. Nonparametric tests were performed using the Wilcoxon-signed rank test to determine the difference between the baseline and 6-month follow-up data, and the Wilcoxon rank sum test was used to examine the differences between the two groups. The proportion of participants who smoke, drink, and use drug was presented using the chi-square test, which determined the difference between the two groups. Spearman's rank correlation coefficients were used to explore associations between myostatin and other variables. Percent change of variables was calculated using the formula:

$$
\% \text { change }=([6-\text { month value }- \text { baseline value }] /[\text { baseline value }] \times 100)
$$

$\mathrm{P}$-values less than 0.05 were considered statistically significant. All analyses were performed using the R statistical package (R Development Core Team 2008).

\section{Results}

The patients' characteristics at baseline were similar between the groups for all factors. The main characteristics of the participants are shown in Table 1. The changes in variables between baseline and 6-month in the two groups are shown in Table 2. After the 6-month intervention program, there was a significant increase in the SMI in the supplement group ( $\mathrm{p}=0.02)$, but the SMI in the non-supplement group did not exhibit a significant change. The mean serum myostatin level $(483.78 \mathrm{ng} / \mathrm{ml})$ increased significantly in the non-supplement group $(\mathrm{p}=0.01)$, but it did not significantly increase in the supplement group $(\mathrm{p}=0.1)$. The change of the serum myostatin level was significantly different between the two groups $(\mathrm{p}=0.001)$. There was no significant relationship between the change in myostatin level and the change in SMI scores, bone mineral density, and total lean mass. The serum vitamin $\mathrm{D}$ level increased significantly ( $\mathrm{p}=0.03$; supplement $>$ non-supplement). The BMD and BMC did not change significantly from baseline to the 6-month follow-up in both groups, but there was a significant difference of BMD between the two groups ( $p=0.03$, supplement $>$ non-supplement); Figure 2 . The SMI response was significantly different between baseline and at the 6-month interval, with a difference of $2.52 \%(0.64 \% ; 5.24 \%)$ [median (lower; upper quartile)] in the supplement group ( $\mathrm{p}=0.02)$, but not in the non-supplement group $(\mathrm{p}=0.43)$. Leg strength also showed the crucial change between baseline and at the 6-month interval in the supplement group $(\mathrm{p}=0.05)$, and in the non-supplement group $(\mathrm{p}=0.04)$. We did not see any significant improvement in the total lean mass and HGS in either group. No participants experienced an adverse event after taking the amino acid and vitamin D supplements. All participants complied with the intervention. 
Table 1. Comparison of the baseline characteristics of selected variables between the non-supplement and supplement participants

\begin{tabular}{|c|c|c|c|}
\hline Variable & Non-supplement & Supplement & P-value \\
\hline $\mathrm{n}$ & 14 & 15 & \\
\hline Age (years) & $68.00(60.50-72.75)$ & $74.00(67.00-77.00)$ & 0.20 \\
\hline Height (m) & $1.56(1.49-1.62)$ & $1.59(1.53-1.61)$ & 0.45 \\
\hline Body weight (kg) & $58.80(46.78-70.00)$ & $53.40(46.50-58.80)$ & 0.45 \\
\hline BMI $\left(\mathrm{kg} / \mathrm{m}^{2}\right)$ & $23.78(19.36-26.15)$ & $22.08(18.71-23.58)$ & 0.20 \\
\hline $\mathrm{SBP}(\mathrm{mmHg})$ & $136.50(125.75-142.00)$ & $130.00(115.00-169.00)$ & 0.88 \\
\hline $\mathrm{DBP}(\mathrm{mmHg})$ & $75.00(72.00-85.25)$ & $74.00(70.00-95.00)$ & 0.81 \\
\hline Total lean mass (kg) & $34.95(30.54-43.89)$ & $34.75(31.82-41.19)$ & 0.85 \\
\hline Legs muscle mass (kg) & $11.05(9.56-13.75)$ & $11.79(9.97-13.07)$ & 0.75 \\
\hline Arms muscle mass $(\mathrm{kg})$ & $3.13(2.85-4.16)$ & $3.39(2.87-4.14)$ & 0.71 \\
\hline Skeletal muscle index & $6.50(5.40-6.87)$ & $6.15(5.17-6.51)$ & 0.31 \\
\hline Hand grip strength (kg) & $21.00(18.31-24.55)$ & $20.50(17.70-26.83)$ & 0.91 \\
\hline Leg strength (N/kg) & $1.25(1.11 ; 1.29)$ & $1.26(1.09 ; 1.59)$ & 0.75 \\
\hline Usual walking speed $(\mathrm{m} / \mathrm{s})$ & $1.33(1.30-1.39)$ & $1.38(1.20-1.58)$ & 0.29 \\
\hline \multicolumn{4}{|l|}{ Smoking status } \\
\hline Never & $12(41.4 \%)$ & $14(48.3 \%)$ & 0.571 \\
\hline Current & $1(3.4 \%)$ & 0 & \\
\hline Past & $1(3.4 \%)$ & $1(3.4 \%)$ & \\
\hline \multicolumn{4}{|l|}{ Drinking status } \\
\hline Never & $12(41.4 \%)$ & $14(48.3 \%)$ & 0.501 \\
\hline Current & $2(6.9 \%)$ & $1(3.4 \%)$ & \\
\hline Past & 0 & 0 & \\
\hline \multicolumn{4}{|l|}{ Drug usage } \\
\hline Hypertension & $2(6.9 \%)$ & $4(13.8 \%)$ & 0.411 \\
\hline Hyperlipidemia & $1(3.4 \%)$ & $1(3.4 \%)$ & 0.960 \\
\hline
\end{tabular}

Notes. BMI, Body mass index; SBP, Systolic blood pressure; DBP, Diastolic blood pressure; Values shown are median, lower, and upper quartiles, and percent (in parentheses). P-values were derived from Wilcoxon rank sum test and chi-square test for difference between the two groups. 
Table 2. Comparison of selected variables between the non-supplement and supplement groups at baseline and at 6-month follow-up

\begin{tabular}{|c|c|c|c|c|}
\hline & \multicolumn{2}{|c|}{ Non-supplement } & \multicolumn{2}{|c|}{ Supplement } \\
\hline \multirow{2}{*}{$\begin{array}{c}\mathrm{n} \\
\text { Variable }\end{array}$} & \multicolumn{2}{|c|}{14} & \multicolumn{2}{|c|}{15} \\
\hline & Baseline & $6^{\text {th }}$ month & Baseline & $6^{\text {th }}$ month \\
\hline Body weight $(\mathrm{kg})$ & $55.80(46.78 ; 70.0)$ & $56.25(46.95 ; 66.10)$ & $53.40(46.50 ; 58.80)$ & $54.00(46.50 ; 56.70)$ \\
\hline $\mathrm{SBP}(\mathrm{mmHg})$ & $136.50(125.75 ; 142)$ & $138.00(123 ; 147.50)$ & $130.0(115.0 ; 169.0)$ & $132(124.75 ; 144)$ \\
\hline $\mathrm{DBP}(\mathrm{mmHg})$ & $75.00(72.00 ; 85.25)$ & $75.50(71.75 ; 83.00)$ & $74.00(70.00 ; 95.00)$ & $81.5(67.50 ; 86.25)$ \\
\hline $\operatorname{BMI}\left(\mathrm{kg} / \mathrm{m}^{2}\right)$ & $23.78(19.36 ; 26.15)$ & $23.27(19.75 ; 25.94)$ & $22.08(18.71 ; 23.58)$ & $21.53(19.05 ; 23.83)$ \\
\hline Leg strength (N/kg) & $1.25(1.11 ; 1.29)$ & $1.39(1.29 ; 1.53)^{*}$ & $1.26(1.09 ; 1.59)$ & $1.48(1.16 ; 1.66)^{*}$ \\
\hline $\begin{array}{l}\text { Total muscle mass } \\
(\mathrm{kg})\end{array}$ & $34.95(30.54 ; 43.89)$ & $36.64(31.43 ; 42.17)$ & $34.74(31.81 ; 41.19)$ & $36.15(32.56 ; 40.91)$ \\
\hline $\begin{array}{l}\text { Arms muscle mass } \\
(\mathrm{kg})\end{array}$ & $3.03(2.88 ; 3.79)$ & $3.29(2.86 ; 4.09)$ & $3.19(2.87 ; 4.14)$ & $3.47(2.94 ; 4.17)^{*}$ \\
\hline $\begin{array}{l}\text { Legs muscle mass } \\
(\mathrm{kg})\end{array}$ & $10.45(9.41 ; 12.67)$ & $10.58(9.37 ; 13.11)$ & $11.35(9.97 ; 12.87)$ & $11.60(10.36 ; 13.21)^{*}$ \\
\hline $\mathrm{SMI}\left(\mathrm{kg} / \mathrm{m}^{2}\right)$ & $5.77(5.41 ; 6.21)$ & $6.08(5.38 ; 6.47)$ & $6.15(5.18 ; 6.51)$ & $6.40(5.38 ; 6.70)^{*}$ \\
\hline $\mathrm{BMC}(\mathrm{g})$ & $1860(1647.50 ; 2381.25)$ & $1787(1456.25 ; 2327.75)$ & $1893(1550 ; 2090)$ & $1977(1623 ; 2600)$ \\
\hline Vitamin D (ng/ml) & $14(13 ; 18.75)$ & $16(13.75 ; 21)$ & $17(14 ; 20)$ & $26(18 ; 31)^{* *}$ \\
\hline Myostatin (ng/ml) & $2.83(2.09 ; 3.06)$ & $3.26(2.76 ; 3.56)^{*}$ & $2.60(2.31 ; 3.59)$. & $2.41(2.14 ; 2.83)$ \\
\hline
\end{tabular}

Notes. SBP, Systolic blood pressure; DBP, Diastolic blood pressure; BMI, Body mass index; SMI, Skeletal muscle index; BMC, Bone mineral content; Values shown are median, lower and upper quartiles (in parentheses). ${ }^{*} \mathrm{P}<0.05,{ }^{*} \mathrm{P}<0.01$, $\mathrm{P}$-values were derived from Wilcoxon signed-rank test for difference between baseline and 6-month.

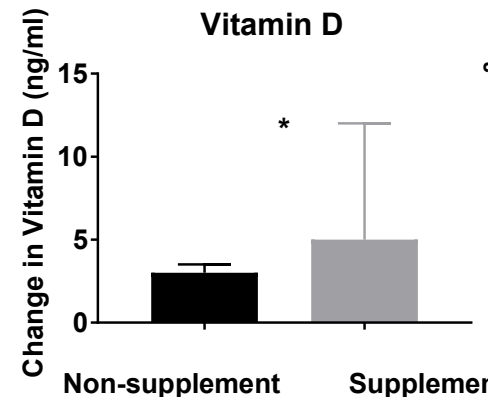

Non-supplement
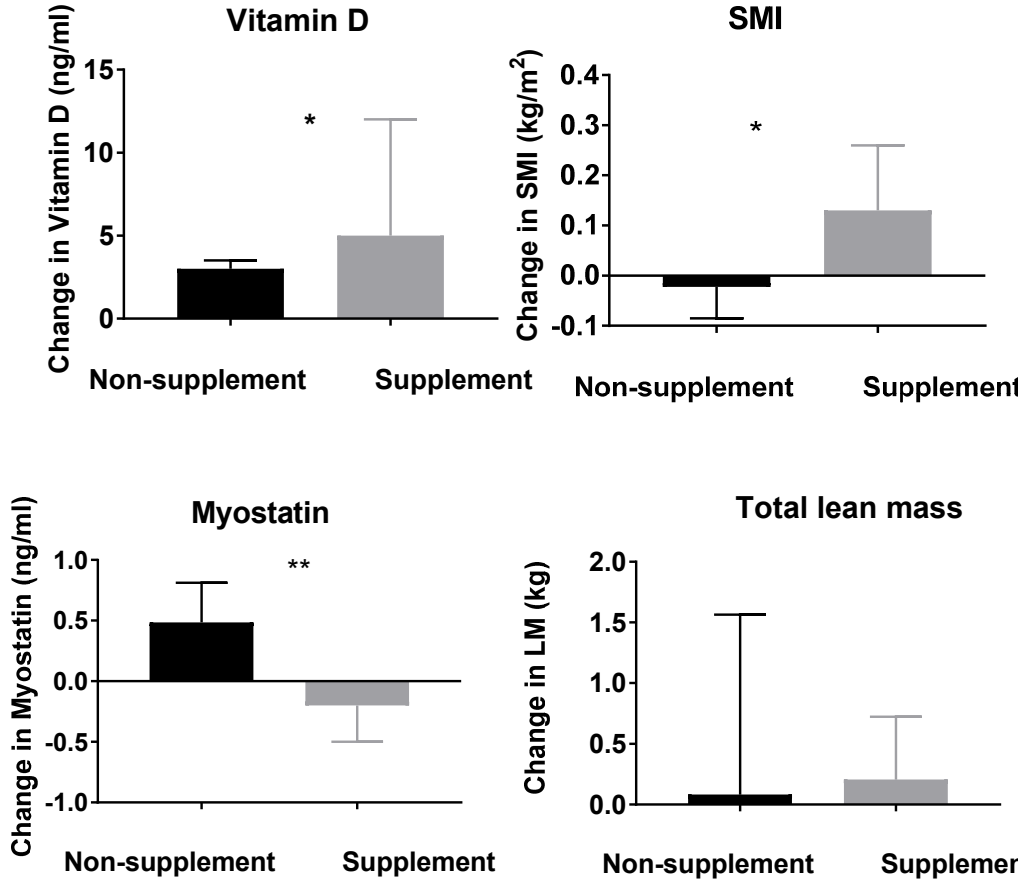

Total lean mass

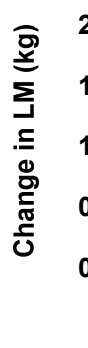

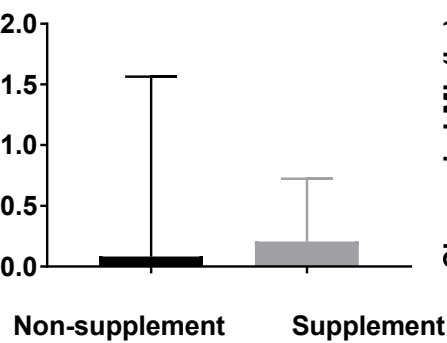

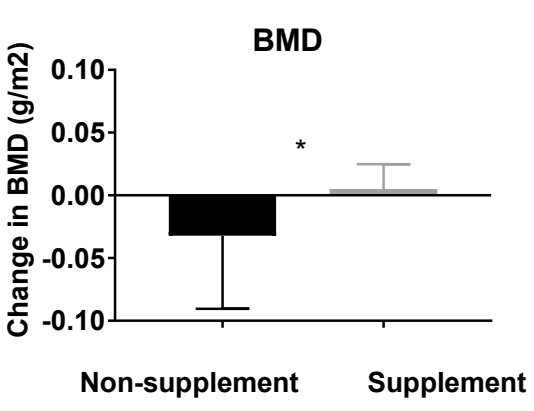

Non-supplement

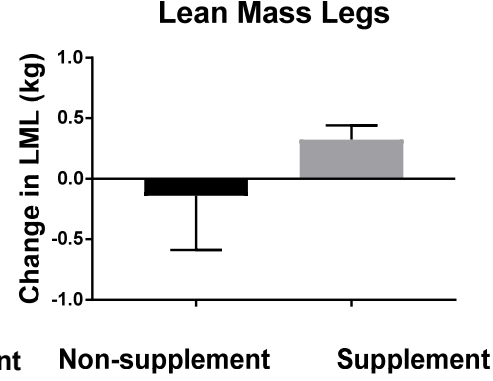

Figure 2. Mean changes in vitamin D, myostatin, skeletal muscle index, total lean mass, bone mineral density, bone mineral content after the intervention. Bars indicate average changes from baseline to the 6-month follow-up; error bars represent the lower and upper quartile. BMD, bone mineral density; SMI, skeletal muscle index; LM, total lean mass; LML, lean mass legs. $* \mathrm{P}<0.05$, $* * \mathrm{P}=0.01$, $\mathrm{P}$-values were derived from Wilcoxon rank sum test for difference between the two groups 


\section{Discussion}

In this study, low muscle volume was defined based on the declines in the SMI. Our discussion focuses on the effects of the intervention as exploring pre-sarcopenia was the initial aim of this investigation. Many researchers performed investigations that focused on exercise and nutritional intake to control the decline of muscle mass and strength in patients with sarcopenia (Campbell, Crim, Dallal, Young, \& Evans, 1994; Arnal et al., 1999; Kim et al., 2012; Rondanelli et al., 2016), but the results of these studies have not always been consistent (Kerstetter et al., 2005; Dillon et al., 2009; Paddon-Jones \& Rasmussen, 2009). Our study demonstrates that the arm and leg muscle mass, hand grip strength, and walking speed did not increase with combined exercise and amino acid ingestion in both groups; however, the SMI improved only in the exercise and amino acid supplement group.

The Recommended Dietary Allowances (RDA) for dietary protein is based on the level of protein that is required to achieve nitrogen equilibrium; it was originally $1.0 \mathrm{~g} / \mathrm{kg}$ until the $1980 \mathrm{RDA}$ guideline and was subsequently decreased to $0.80 \mathrm{~g} / \mathrm{kg}$. Significant evidence suggests that the current recommendations for dietary protein in elderly people ( $\geq 65$ years old) are inadequate for optimal muscle and bone health (Campbell et al., 1994). These studies assessed the effects of different amino acid doses (between 6.70 and $20 \mathrm{~g} /$ day) on protein synthesis, and the $6.0-\mathrm{g} /$ day dose that was provided in our study is lower than that in previous studies; however, the mean weight of the subjects in those studies was between 71.0 and $81.3 \mathrm{~kg}$, and the amino acid dose was between 0.09 and 0.25 $\mathrm{g} / \mathrm{kg}$ of the participants' weight. Our study used an amino acid dose of $0.11 \mathrm{~g} / \mathrm{kg}$, which is comparable with the doses used in the literature. Our study showed that the SMI was significantly increased in the supplement group, which is consistent with results of the previous investigations.

The increase in muscle mass due to nutritional supplementation was indicated in many studies; however, an increase in muscle strength does not always follow an increase in muscle mass. Although the current research showed that amino acid supplements combined with exercise increased the SMI and serum vitamin D level, as well as reduced the level of myostatin, an enhancement in muscle strength was observed in the leg strength. The improvement in single variables, such as leg muscle mass or the usual walking speed, knee extension strength can be observed in the exercise without supplement group (Peterson et al., 2010; Kim et al., 2012). However, rationally, improvements in single variables are not sufficient to treat sarcopenia. Although it is inconclusive whether exercise combined with an amino acid supplement is better than either intervention alone, these results suggest that exercise and amino acid supplementation may be necessary to gain muscle mass and muscle power.

This study has novel aspects due to its focus on body composition, bone mass, and supplement use. Elderly people must increase the anabolic stimulus and consume $30 \mathrm{~g}$ of protein per meal to prevent protein catabolism (Dillon et al., 2009; Paddon-Jones et al., 2009). The amino acid leucine stimulates skeletal muscle protein synthesis (Volpi et al., 1998). An increase in myostatin concentrations inhibits muscle growth. This is because myostatin is possibly the most predominant mediator of muscle growth and repair. Furthermore, in our study, the non-supplement participants exhibited a significant increase in the mean serum myostatin level $(\mathrm{p}=0.02)$, which may be due to the fact that the protein synthesis rate was low in this group. The myostatin level and the protein synthesis rate may be contributed to the building of muscle skeletal mass. Resistance training promoted significant enhancements in muscle strength, muscle power in elderly (Lopez et al., 2017), but not muscle skeletal mass. Otherwise, non-supplement participants may have low protein intake due to the absence of nutrition support and supplement. The expression of myostatin increment to restrict the enhancement of muscle tissue amid the procedure of muscular growth (Han et al., 2011). We did not find any significant relationship between myostatin and the SMI, which may be due to the fact that the dose of myostatin and the myostatin receptor were not well coordinated.

A recent meta-analysis (Beaudart et al., 2014) indicated the growth of muscle strength by $17 \%$ on average due to daily supplementation with $400 \mathrm{IU}$ of vitamin D3. The supplement that we used contained $200 \mathrm{mcg}$ (800 IU) of vitamin $\mathrm{D}$. We used this dose of vitamin $\mathrm{D}$ because the mean age of the patients was 70 , and the dose indicated for this age group is $800 \mathrm{IU}$ of vitamin $\mathrm{D}$ daily to prevent bone loss; furthermore, these participants also participated in indoor training (Cranney et al., 2008).

The present study's findings must be interpreted within the context of its strengths and potential weaknesses. The participant's body composition was measured using DXA technology, which is considered the gold standard method for assessing body composition. We also measured the serum vitamin D and myostatin levels, which could allow for a better evaluation of muscle and bone metabolism. However, we used a small sample size, and we could not conduct subgroup analyses to examine the effect of the intervention in smaller groups of participants. Our study also did not have non-exercise and non-supplement groups to act as controls; otherwise, the effect of home exercise was not estimated, therefore, it is possible that the effect observed here may be an overestimation of the true effect sizes. Three people dropped out of the study, and they were excluded from the data analysis. However, 
there were no significant differences between participants who withdrew from the study and those who completed the study. The duration of follow-up was only 6 months, and we were not able to ascertain the long-term effect of this intervention program. Furthermore, the effects of vitamin D supplement independently from amino acid supplement were not examined due to the small sample size.

\section{Conclusion}

The results of this study suggest that amino acid combined vitamin D supplement with resistance exercise can produce changes in catabolic and anabolic mediators, thereby lowering muscle inhibitor markers such as myostatin and improving serum vitamin D. This shift resulted in a significant increase in the SMI $(+2.78 \%)$ and BMD $(+4.34 \%)$, proving that the intervention is effective for treating low muscle mass and preventing sarcopenia, with improvements in the SMI and muscle power. Further follow-up studies that emphasize nutritional intake, with home exercise recording, with a bigger sample size, and having a control group without exercise are required to confirm these results.

\section{Grant}

This study was supported by a Rotary Yoneyama Scholarship to HC.

\section{Authors' Contributions}

HC responded for designing the study and wrote the manuscripts. HT, SY, AK, NT were responsible for monitoring the study and recording the data. SK, $\mathrm{HC}, \mathrm{KO}$ were responsible for performing experiments and data analysis. KH, TK, YF, KN assisted in writing the manuscript. YK approved the final version.

\section{Acknowledgments}

The authors express their gratitude to the staff members of the Health Science Center of KMU Hospital for the assistance.

\section{Competing Interests Statement}

The authors declare that they have no conflicts of interest with respect to this paper.

\section{References}

Arnal, M. A., Mosoni, L., Boirie, Y., Houlier, M. L., Morin, L., Verdier, E., ... \& Mirand, P. P. (1999). Protein pulse feeding improves protein retention in elderly women. The American Journal of Clinical Nutrition, 69(6), 1202-1208. PMID: 10357740

Bauer, J., Biolo, G., Cederholm, T., Cesari, M., Cruz-Jentoft, A. J., Morley, J. E., ... \& Visvanathan, R. (2013). Evidence-based recommendations for optimal dietary protein intake in older people: a position paper from the PROT-AGE Study Group. Journal of the American Medical Directors Association, 14(8), 542-559. https://doi.org/10.1016/j.jamda.2013.05.021

Beaudart, C., Buckinx, F., Rabenda, V., Gillain, S., Cavalier, E., Slomian, J., ... \& Bruyère, O. (2014). The effects of vitamin D on skeletal muscle strength, muscle mass, and muscle power: a systematic review and meta-analysis of randomized controlled trials. The Journal of Clinical Endocrinology \& Metabolism, 99(11), 4336-4345. https://doi.org/10.1210/jc.2014-1742

Børsheim, E., Bui, Q. U. T., Tissier, S., Kobayashi, H., Ferrando, A. A., \& Wolfe, R. R. (2008). Effect of amino acid supplementation on muscle mass, strength and physical function in elderly. Clinical Nutrition, 27(2), 189-195. https://doi.org/10.1016/j.clnu.2008.01.001

Campbell, W. W., Crim, M. C., Dallal, G. E., Young, V. R., \& Evans, W. J. (1994). Increased protein requirements in elderly people: new data and retrospective reassessments. The American Journal of Clinical Nutrition, 60(4), 501-509. PMID: 8092084

Candow, D. G., Forbes, S. C., Little, J. P., Cornish, S. M., Pinkoski, C., \& Chilibeck, P. D. (2012). Effect of nutritional interventions and resistance exercise on aging muscle mass and strength. Biogerontology, 13(4), 345-358. https://doi.org/10.1007/s10522-012-9385-4

Ceglia, L. (2009). Vitamin D and its role in skeletal muscle. Current Opinion in Clinical Nutrition and Metabolic Care, 12(6), 628. https://doi.org/10.1007/s00223-012-9645-y

Cerri, A. P., Bellelli, G., Mazzone, A., Pittella, F., Landi, F., Zambon, A., \& Annoni, G. (2015). Sarcopenia and malnutrition in acutely ill hospitalized elderly: Prevalence and outcomes. Clinical Nutrition, 34(4), 745-751. https://doi.org/10.1016/j.clnu.2014.08.015 
Cranney, A., Weiler, H. A., O'donnell, S., \& Puil, L. (2008). Summary of evidence-based review on vitamin D efficacy and safety in relation to bone health. The American Journal of Clinical Nutrition, 88(2), 513S-519S. PMID: 18689393

Cruz-Jentoft, A. J., Baeyens, J. P., Bauer, J. M., Boirie, Y., Cederholm, T., Landi, F., ... Zamboni, M. (2010). Sarcopenia: European consensus on definition and diagnosis: Report of the European Working Group on Sarcopenia in Older People. Age and Ageing, 39(4), 412-423. https://doi.org/10.1093/ageing/afq034

Dillon, E. L., Sheffield-Moore, M., Paddon-Jones, D., Gilkison, C., Sanford, A. P., Casperson, S. L., ... \& Urban, R. J. (2009). Amino acid supplementation increases lean body mass, basal muscle protein synthesis, and insulin-like growth factor-I expression in older women. The Journal of Clinical Endocrinology \& Metabolism, 94(5), 1630-1637. https://doi.org/10.1210/jc.2008-1564

Fiatarone, M. A., O'Neill, E. F., Ryan, N. D., Clements, K. M., Solares, G. R., Nelson, M. E., ... \& Evans, W. J. (1994). Exercise training and nutritional supplementation for physical frailty in very elderly people. New England Journal of Medicine, 330(25), 1769-1775. https://doi.org/10.1056/nejm199406233302501

Forbes, S. C., Little, J. P., \& Candow, D. G. (2012). Exercise and nutritional interventions for improving aging muscle health. Endocrine, 42(1), 29-38. https://doi.org/10.1007/s12020-012-9676-1

Houston, D. K., Nicklas, B. J., Ding, J., Harris, T. B., Tylavsky, F. A., Newman, A. B., ... \& Kritchevsky, S. B. (2008). Dietary protein intake is associated with lean mass change in older, community-dwelling adults: the Health, Aging, and Body Composition (Health ABC) Study. The American Journal of Clinical Nutrition, 87(1), 150-155. PMID: 18175749

Han, D. S., Chen, Y. M., Lin, S. Y., Chang, H. H., Huang, T. M., Chi, Y. C., \& Yang, W. S. (2011). Serum myostatin levels and grip strength in normal subjects and patients on maintenance haemodialysis. Clinical Endocrinology, 75(6), 857-863. https://doi.org/10.1111/j.1365-2265.2011.04120.x

Iannuzzi-Sucich, M., Prestwood, K. M., \& Kenny, A. M. (2002). Prevalence of sarcopenia and predictors of skeletal muscle mass in healthy, older men and women. The Journals of Gerontology Series A: Biological Sciences and Medical Sciences, 57(12), M772-M777. https://doi.org/10.1093/gerona/57.12.m772

Kerstetter, J. E., O’brien, K. O., Caseria, D. M., Wall, D. E., \& Insogna, K. L. (2005). The impact of dietary protein on calcium absorption and kinetic measures of bone turnover in women. The Journal of Clinical Endocrinology \& Metabolism, 90(1), 26-31. https://doi.org/10.1210/jc.2004-0179

Kim, H. K., Suzuki, T., Saito, K., Yoshida, H., Kobayashi, H., Kato, H., \& Katayama, M. (2012). Effects of exercise and amino acid supplementation on body composition and physical function in community dwelling elderly Japanese sarcopenic women: a randomized controlled trial. Journal of the American Geriatrics Society, 60(1), 16-23. https://doi.org/10.1111/j.1532-5415.2011.03776.x

Latham, N. K., Anderson, C. S., \& Reid, I. R. (2003). Effects of vitamin D supplementation on strength, physical performance, and falls in older persons: a systematic review. Journal of the American Geriatrics Society, 51(9), 1219-1226. https://doi.org/10.1046/j.1532-5415.2003.51405.x

Latham, N. K., Bennett, D. A., Stretton, C. M., \& Anderson, C. S. (2004). Systematic review of progressive resistance strength training in older adults. The Journals of Gerontology Series A: Biological Sciences and Medical Sciences, 59(1), M48-M61. https://doi.org/10.1519/00139143-200225030-00016

Liu, C. J., \& Latham, N. K. (2009). Progressive resistance strength training for improving physical function in older adults. The Cochrane Library. https://doi.org/10.1002/14651858.cd002759.pub2

Lopez, P., Pinto, R. S., Radaelli, R., Rech, A., Grazioli, R., Izquierdo, M., \& Cadore, E. L. (2017). Benefits of resistance training in physically frail elderly: a systematic review. Aging clinical and experimental research, 1-11. https://doi.org/10.1007/s40520-017-0863-Z

Morley, J. E., Baumgartner, R. N., Roubenoff, R., Mayer, J., \& Nair, K. S. (2001). Sarcopenia. Journal of Laboratory and Clinical Medicine, 137(4), 231-243. https://doi.org/10.1067/mlc.2001.113504

Muir, S. W., \& Montero - Odasso, M. (2011). Effect of vitamin D supplementation on muscle strength, gait and balance in older adults: a systematic review and meta - analysis. Journal of the American Geriatrics Society, 59(12), 2291-2300. https://doi.org/10.1111/j.1532-5415.2011.03733.x

Paddon-Jones, D., \& Rasmussen, B. B. (2009). Dietary protein recommendations and the prevention of sarcopenia: protein, amino acid metabolism and therapy. Current Opinion in Clinical Nutrition and Metabolic Care, 12(1), 86. https://doi.org/10.1097/mco.0b013e32831cef8b 
Peterson, M. D., Rhea, M. R., Sen, A., \& Gordon, P. M. (2010). Resistance exercise for muscular strength in older adults: a meta-analysis. Ageing Research Reviews, 9(3), 226-237. https://doi.org/10.1016/j.arr.2010.03.004

Rondanelli, M., Klersy, C., Terracol, G., Talluri, J., Maugeri, R., Guido, D., ... \& Perna, S. (2016). Whey protein, amino acids, and vitamin D supplementation with physical activity increases fat-free mass and strength, functionality, and quality of life and decreases inflammation in sarcopenic elderly. The American Journal of Clinical Nutrition, 103(3), 830-840. https://doi.org/10.3945/ajcn.115.113357

Schaap, L. A., Pluijm, S. M., Deeg, D. J., \& Visser, M. (2006). Inflammatory markers and loss of muscle mass (sarcopenia) and strength. The American Journal of Medicine, 119(6), 526-e9. https://doi.org/10.1016/j.amjmed.2005.10.049

Team, R. C. (2014). R: a language and environment for statistical computing. Vienna, Austria: R foundation for statistical computing; 2014. Retrieved September 15, 2017 from http://www.R-project.org.

Volpi, E., Ferrando, A. A., Yeckel, C. W., Tipton, K. D., \& Wolfe, R. R. (1998). Exogenous amino acids stimulate net muscle protein synthesis in the elderly. Journal of Clinical Investigation, 101(9), 2000. https://doi.org/10.1172/jci939

Waters, D. L., Baumgartner, R. N., Garry, P. J., \& Vellas, B. (2010). Advantages of dietary, exercise-related, and therapeutic interventions to prevent and treat sarcopenia in adult patients: an update. Clinical Interventions in Aging, 5, 259. https://doi.org/10.2147/cia.s6920

Wicherts, I. S., van Schoor, N. M., Boeke, A. J. P., Visser, M., Deeg, D. J., Smit, J., ... \& Lips, P. (2007). Vitamin D status predicts physical performance and its decline in older persons. The Journal of Clinical Endocrinology \& Metabolism, 92(6), 2058-2065. https://doi.org/10.1210/jc.2006-1525

\section{Copyrights}

Copyright for this article is retained by the author(s), with first publication rights granted to the journal.

This is an open-access article distributed under the terms and conditions of the Creative Commons Attribution license (http://creativecommons.org/licenses/by/4.0/). 